\title{
The impact of editorial policies and journal models on social humanities and communication studies related to Covid-19; Evidence from international and Indonesian scholarly work
}

Mahfud Anshori

Communication Department, Faculty of Social and Political Science, Universitas Sebelas Maret, Indonesia

Email: mahfudanshori_fisip@staff.uns.ac.id

Henricus Hans Setyawan Prabowo

Applied Communication, Vocational School, Universitas Sebelas Maret, Indonesia

Email: henricushans@staff.uns.ac.id

\begin{abstract}
This study examines scientific publications during a pandemic through bibliometric network analysis. We explored three different journal databases to map COVID-19 research in humanities and social sciences, then zoom in to communication studies. Government policy, e-learning, anxiety, economic impact are popular keywords in international and Indonesian articles on Social and Humanities, while disinformation, health communication, behavior change, and literacy are more prominent in communication articles. The researcher chose the keyword occurrence analysis as the basis for mapping the research theme. The bibliographic network was deployed in three strategies to obtain keyword data co-occurrence from research abstracts, keywords from
\end{abstract}


researchers, and coder's approval keywords. Lastly, Vos viewer is used to creating macro and detailed perspective networks for interpretation. The results show that journal policies and models affect the number of COVID-19 publications in the journal. Finally, this study provides an overview that normative theory and behaviorism play a role in social and communication research.

Keywords: Covid-19, Communication, Editorial Policy, Education in Indonesia, Social Humanities

\section{Introduction}

Since the outbreak first case of Coronavirus 19 (COVID-19) disease in Wuhan, China, on November 17th, 2019, humans entered a new history in health history that it never been predicted before. Everyone monitored the cases from television stations, newspapers, and social media every second, including how the Chinese government has handled the case, from medical efforts to the lockdown; from conspiracy rumors to government policy.

The virus vast widespread in various countries in Asia, Australia, and Europe. Until March 2021, according to the COVID-19 real-tracking provider at Johns Hopkins University, 192 countries had been declared infected by this variant of coronavirus, with a total of $114,799,870$ people in the world infected with the Covid virus 2,550,344 died and 64,943,628 recovered. In Indonesia, there 1,347,026 infected people, and 36,518 were deceased(Johns Hopkins University, 2021). This global pandemic also had a tremendous impact, starting from the health service system, education, socio-culture, and economy. Every country seems to be competing with time in social restrictions (lockdown), increasing hospital capacity, finding and making vaccines, including deploying the military to prevent people's mobility. Public transportation, business, education, and entertainment and tourism sectors suddenly halted to cuts off viruses in human transmission.

The COVID-19 virus has a profound impact on higher education research. This impact is not only because this theme provides many opportunities for new research, but also the increasing number of publications and publication errors have become an ethical concern. Mansourzadeh \& Shams (2020) noted that the impact of COVID-19-related articles causes academic problems ranging from the retraction of research articles due to incorrect data, citation techniques, and inappropriate data instruments. 
Furthermore, Soltani \& Patini (2020) found that horse racing-related publications on COVID 19 had prompted the retraction of published articles, even though these articles had become a leading academic debate. He also found a case where an article retracted because they indicated it was also published in other journals by other researchers.

As for moderate issues, corrections have increased as the publication of COVID-19 articles ranging from the author identity, the contents of the article, tables, images to changes in keywords. (Moradi \& Abdi, 2020). Even though the correction was not an academic failure, it both the author's and publisher's negligence regarding the fast-paced publication.

This study aims to determine other factors apart from the rapid publication of journal articles during the Covid 19 pandemic. Knowing the factors that affect the quality and theme of journal publications during a pandemic will provide more perspectives, that the speed of publication is not the single factor that affects the quality of journal publications. The author hypotheses that there are more subtle factors than horse racing publications: editorial policies, journal models, and different issues in understanding Covid 19 from a social humanities perspective.

By comparing the data between articles indexed in international databases with national databases in Indonesia, the researchers attempt to find a description of editorial policies and types of journals that affect research themes.

We also map research based on social science disciplines and humanities and zoom-in in communication studies; to obtain an overview of the developing research themes related to COVID 19 from social research and communication.

\section{Literature Review}

Watson (1958) has been described and predicted the editorial factors and the decline in the quality of journal articles since the rise of the internet era. In the 70s, editorial scientific journals had faced an increase in article manuscript, a bulk of article submission, and the trend of citing bibliographies that were fat but not accompanied by quality content. They also find the tendency of non-single authors and the accuracy of writing scientific articles. The shift in the publication medium from print to online considered as a factor that has contributed to changing the publication model rapidly, which on the one hand has the advantage of disseminating journal access, but on the other hand also changing the culture of the publication itself (Kuney, 1970). 
The issue of scientific publishing in higher education remain until the 90s, including the historical study of the role of peer review in scientific journals(Kronick, 1990), lengthy abstracts (Sobal, Jefferey, Ferentz, 1990), influence computers and information technology in writing journal articles and publications(Harnad, 1990; Odlyzko, 1995) as well as the credibility of journals published by commercial institutions in e-journal format(Metz \& Gherman, 1991).

Recently, the study of scientific journal articles has much to do with the dissemination of journal articles. Abby A. Goodrum et.al.(2001) examined the role of the internet and the practice of journal citation in the computer science research community. They realize that the academic community moderated by information technology affects the process of producing scientific journal articles. They also found that the automatic indexation of the citation influences the dissemination of articles among researchers.

Furthermore, Ziming Liu (2003) found that collaboration writers are becoming a trend among researchers as evidence of the democratization of knowledge hierarchies, increased equitable participation, and greater sharing of resources. Zimming also found evidence that the exponential growth of publication shortens the life of article citations. The number of uncited articles increased dramatically because of the rapid growth of publication.

Meanwhile, Eric L.Dey et al (2016) have studied the relationship between bureaucratic institutions and scientific publications. Using two concepts about accumulative benefits and similarity in forms and institutional relationships, they placed the scientific publications on two binary sides; first, articles as a predominance of researchers/institutions and second as a form of teamwork that encourages similarity between research institutions. Here, collaboration research leads to the similarity between the authors, which forces the researchers to work harder and join elite research groups.

This elitist tendency can also found in the writer and editor of the journal. Researching four major sociology journals, Robert Perrucci et al.(2019) see that journal publishers over a period of 50 years tend to provide more space for writers and editors from top-ranking educational institutions compared to other colleagues. The different missions of a journal also determine the selection of editors and writers. Independent journals tend to choose editors and writings from top-ranking universities, and only one journal is more open than editors and writers from non-elite departments. Rochman Achwan et al (2020) highlighted that state-led university reform has driven changes in social 
science studies in Indonesia, where researchers have started international research networks by affirming efforts to elevate non-western theory as a competitive culture and excellence.

This study reflects the impact of editorial policies and theme issues in a pandemic situation. We using bibliometrics to analyze social and communication themes and provide a theoretical picture of developing issues and how to predict changes in studies in the future (2011).

\section{Methods}

There are two approaches to studying the academic literature, systematic reviews, and bibliometric networks. A systematic review examines an article's content deeply when bibliometric networks focus on scientific networks based on text. The bibliometric mapping tries to obtain patterns, trends, and relationships in keywords. The second approach examines networks from the citation, co-citation, bibliographic coupling, author network, and co-keyword occurrence.

Since this study relied on research themes regarding the COVID-19 issue, the researchers chose co-keyword occurrence analysis as the basis for the research map analysis.

We selected three strategies to obtain keyword data co-occurrence i.e.:research abstracts, keywords from researchers, and coder's approval keywords. We chose these strategies to eliminate the indexer effect. The indexer effect is an effect due to keywords personally generated by the researcher and the indexer manual/data. We implemented co-occurrence keyword analysis to obtain a broad picture of research themes and create a visual map of terms and the relations.

To be more specific in looking at the COVID-19 research map, we employing bibliometric networks and map visualization using the software VOSviewer from the Center for Science and Technology Studies, Leiden University. We analyzed keywords in co-occurrence and visualized them in VOSviewer. Vos Viewer is considered by many to be easier to read than other similar applications.

\section{Data Collection}

The data was collected range from December 2019 to January 2021. It was scientific publication articles in various journals in Indonesia. We retrieved 
and extracted manually for 47021 articles at two database providers; the Garuda portal (https://garuda.ristekbrin.go.id/) and Google Scholar (https://scholar. google.com/).

In selecting these articles, the researcher used the search keywords "COVID-19 " for the Garuda portal and "COVID-19 " AND "Indonesia" for Indonesia Google Scholar.

We had trained 5 junior students for retrieving and extracting data from selected sources in two weeks. Students are provided with data retrieval techniques by predetermined protocol manuals, some of which are: a) Journal identity from the Title of Author Name, Published Edition and Publisher must be clear b) Abstracts and keywords must be mutually relevant, c) There is no duplication of articles in one data source. Protocol manuals also allow coders to provide additional keywords if none of the keywords are sufficiently relevant to the article abstract. It is used to increase the degree of abstract and keyword relevance in co-occurrence.

We used intercoder reliability to test data reliability. Two trained coderstudents agreed to a term and determined it was accepted or rejected in-unit analysis. If the two coders had differents agreements, then the researcher justified using personal judgment.

While the datasheet from Scopus, we deployed the keywords combination in "COVID-19"; "media"; "Communication"; and limit to Social and Humanities. We limit the search in the article journal and final publication stage.

The search obtained 7.761 articles. We use the same protocol to tread the Scopus datasheet except for the intercoder keyword process. We skip the intercoder keyword process because the Scopus database has a consistent structure in keyword phrasing. We immediately discard any article without abstracts and other information in the protocol.

We distinguished search keywords from the three data sources based on the relevance of the unit of analysis. Articles from Indonesian journals were grouped manually in communication research based on the descriptions in the abstracts and journal's type on the Garuda Portal and Google Scholar. Whereas on the Scopus datasheet, communication keywords are automatically included in the search stages, to be more specific in obtaining the desired data results. 


\section{Data Conversion}

We have faced non-uniform abstract and keyword data in Indonesian journal publications; there were journal articles that only include abstracts and keywords in Indonesian or English, and some were both, so the researchers decided to use abstracts and keywords in English. For journals that only have abstracts and keywords in Indonesian, the researchers translated manually into English. This decision relied on two considerations; first, Natural Language Processing (NLP) limited to English(Søgaard et al., 2019); second, for comparison purposes with the datasheet from Scopus, it is easier to use English than Bahasa Indonesia.

\section{Data Reduction}

The data reduction is to refine the research datasheet. The steps involved removing data in the following categories: a) duplication occurs, b) incomplete and, c) excluded first. Duplication data is cleaned based on the title, while incomplete data was lacking the author's abstract. Meanwhile, the data types i,e, book chapters, notes, editorials, reviews, paper data, erratum, were removed first before two reduction data. We analyzed 3500 articles related to Humanities and Social Sciences, and Communication Sciences after data fitting.

\section{Data Analysis}

Data were analyzed using a network analysis approach. We build events together in full-counting based on article keywords, both from abstract and author keywords. To prevent the domination of homogeneous keywords (such as "COVID-19"), the researchers chose normalized data using a linear logistic normalization approach. Unless there is too little data, researchers opt for fraction normalization to make keyword relevance more visible.

\section{Results and Discussion}

\section{Publication and Editorial Policy}

The chart in figure 1 and figure. 2 presents the data collection on journals with the highest publications in the Scopus database from 2019 to 2021. We divided these articles into two categories: social humanities journals communication discipline. Each journal with articles in Covid-19 keyword in Social and humanities categories selected and matched the journal name with 
the list journal's rank in communication categories by the Scimago Journal \& Country Rank.

Research data has shown that social sciences, journals with the scope of environmental, cultural, economic, and human social, health and law relatively have more articles on COVID-19 than the other journals.

Sustainability (ISSN 2071-1050; CODEN: SUSTDE); is a multidisciplinary journal published by the MDPI group, a scientific publication group that publishes many journals in various fields. Morbidity and Mortality Weekly Report or MMWR CDC Series (ISSN: 0149-2195 eISSN: 1545-861X)) published in the United States covers the latest report on various health issues in the United States, on behalf Department of Health and Human Services. Meanwhile, Bio Law Journal-Rivista at Bio Diritto (ISSN 22844503) is an interdisciplinary journal in the fields of law, life sciences, and bioethics.

We estimate journal regulations and policies, such as journal vision and coverage, editorial policy, format, and periodicals due to the number of journal articles. The top three journals in figure 1 . are multidisciplinary journals with an open-access journal format. Sustainability is a semi-monthly publication, Bio Law Journal-Rivista at Bio Diritto is quarterly, while the MMWR Series is published every week.

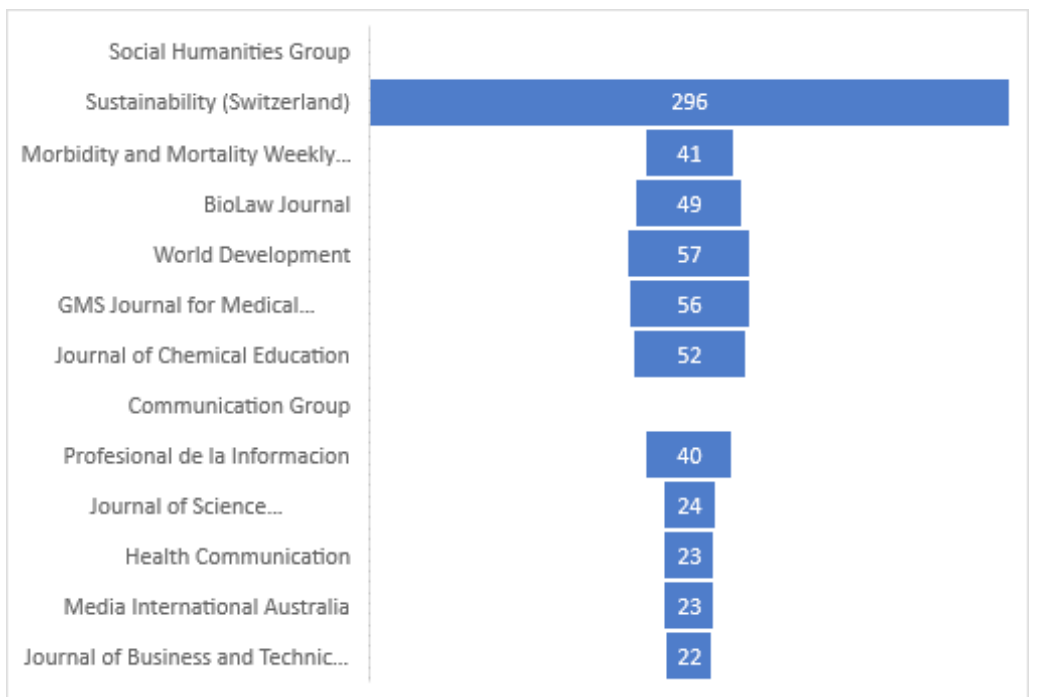

Figure 1. Top five in number of the article in the Social Sciences Humanities group of Communication Studies that publish related articles about COVID-19 until March 2021, based on the Scopus database. 
We found a different policy from the top three journals in communication science that published articles on Covid -19. The professional Journal de la Informacion (ISSN 16992407, 13866710) and the journal Health Communication (ISSN 10410236, 15327027) mode hybrid publication policy, and published bimonthly. The Journal of Science Communication (ISSN 18242049) solely has an open-access policy and does not have a publication time frame.

All of the journals mentioned above have policies to cover COVID 19 research in special editions in both single and multiple editions, besides a regular edition.

Furthermore, we found a tendency for journal articles published in Indonesia related to COVID-19 to were published by and large in educational journals. In this context, we cannot separate the Social Humanities due to the unclear journal categorization in the primary database.

\begin{tabular}{|c|c|}
\hline \multicolumn{2}{|l|}{ Social dan Humanities Group } \\
\hline Jurnal IImu Pendidikan & 135 \\
\hline Cetta : Jurnal IImu Pendidikan & 134 \\
\hline SALAM: Jurnal Sosial dan... & 33 \\
\hline 'Adalah; Buletin Hukum dan... & 22 \\
\hline Indonesian Journal of Science... & 13 \\
\hline Communication Group & \\
\hline Jurnal ASPIKOM & 5 \\
\hline Jurnal Kopis; Kajian Penelitian... & 4 \\
\hline Jurnal Pengembangan IImu... & 4 \\
\hline Jurnal IImu Komunikasi & 4 \\
\hline Jurnal Pengembangan IImu... & 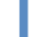 \\
\hline
\end{tabular}

Figure 2. Top five in number of the article in the Social Sciences Humanities group and Journal of Communication Studies that publish related articles about COVID-19 until March 2021, based on the Garuda Portal Database and Google Scholar

Jurnal Imu Pendidikan (ISSN 0215-9643), published by the Universitas Negeri Malang, is a journal that focuses on educational issues with authorsresearchers from the LPTK and Education Center. While Cetta: Jurnal Ilmu Pendidikan(e ISSN: 26150891) is a journal published by Jayapangus Press and issues education at all levels. Meanwhile, there are non-educational social 
sciences and humanities disciplines; a) Salam; Jurnal Sosial dan Budaya Syar'i (SJSBS) (ISSN: 2654-9050) and b) Adalah; Buletin Hukum dan Keadilan (eISSN: 26549050). Salam Journal concern with social and culture in Islamic perspectives, meanwhile Adalah focuses on Islamic law issues. Both of them are published by UIN Syarif Hidayatulah, an Islamic University in Jakarta.

The communication journals in the COVID-19 publication are the Aspikom Journal (eISSN: 25488309) and the Communication Science Journal (ISSN 1693-302). They identify themselves as a communication journal. The Association of Communication Departments in Indonesia pubished Jurnal Aspikom and Jurnal Ilmu Komunikasi from UPN Veteran Yogyakarta. The Kopis Journal (ISSN: 2654315) is an Islamic journal in communication (dakwah) and published by IAI-Tribakti Kediri.

They had around 4-5 articles related to COVID-19 and had similarities in editorial policies, journal's scope, and formats. All of the journals have an Open Acces policy, where most of them use online publication.

\section{Map of research related to COVID-19}

The results from Scopus database related to COVID-19 is divided into three main groups: group 1 ("health", "government policy", "education", "social security", etc.), group 2 ("crisis management", "pandemic" , "crisis communication", "economy", "anxiety", etc.), and group 3 ("communication", "higher education", "curriculum”, "interpersonal communication”, "telemedicine”, "e learning", "media social "etc.)

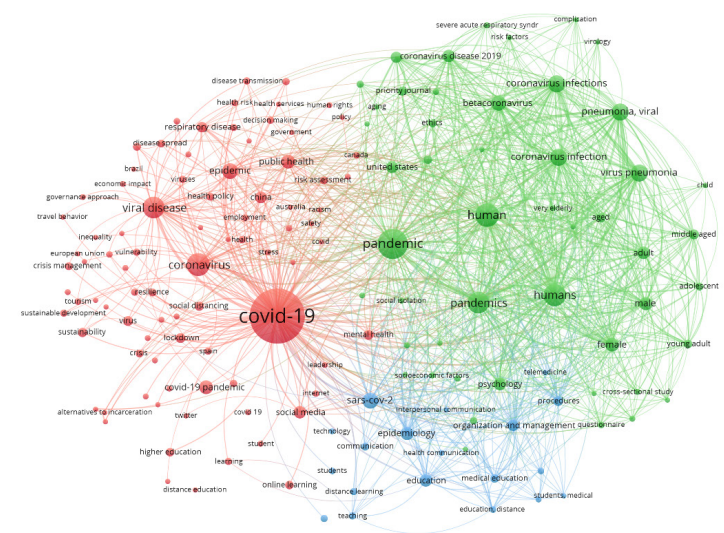

As voswiever

Figure 3. Social and humanities research in the Scopus database 
The first two groups are the dominant group consisting of economic, legal, educational, crisis communication, and health approaches. Whereas COVID-19 articles related to education were about the curriculum changes, the use of social media and e-learning, and distance learning.

Figure 3 shown that COVID-19 articles represent multi-perspectives that generally focus on the impact of COVID-19 in multi-sector life, socio-economic culture, and politics. As a new issue in human history, COVID-19 has social consequences on modern human life. COVID-19 virus, which is transmitted directly between humans, causes humans to redefine social interaction has implications beyond health problems. The research themes in social humanities shown all elements in socio-cultural, political, and economic life have been affected by the pandemic.

Zooming to communication research, there are three main groups of communication studies about COVID-19, namely group 1 ("media content study", "fact checking ", fake news ", " journalism "," social media ", political communication "etc.) group 2 (" health communication "," vulnerable age group "," medical information "," mental health "etc.) and group 2 ("china”, "mass communication”, "viral infection”, "viral”, "pneumonia”).

From figure 4, we have concluded that articles about COVID-19 in Scopus indexed journals in the first cluster highlight crisis communications, especially those related to disinformation (fake news/fake information, misinformation) about COVID-19. Also, some articles question the role of disinformation, surveillance media, health campaigns, and warding off disinformation about COVID-19. Social media problems in political communication and social networking are also in this group, where this is related to mass media and disinformation. 


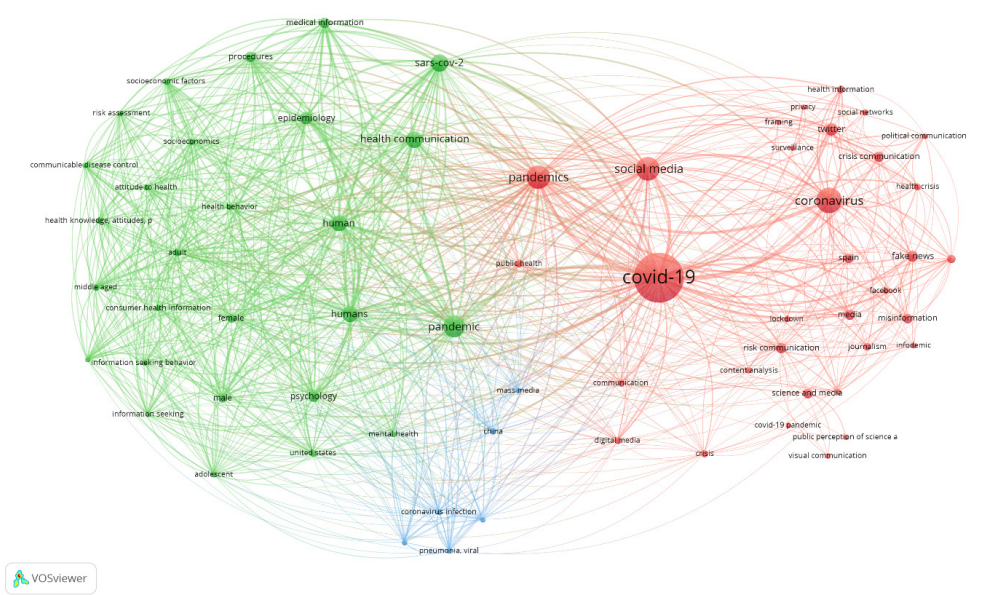

Figure 4 Communication research in the Scopus database

Meanwhile, in the second group, journal articles focus on health communication, especially related to the theme of changes in seeking and exchanging health information, health attitudes and behaviors, and the relationship between these behavioral changes and socio-economic conditions.

The third group is articles that examine a lot of mass media relations in reporting on the COVID-19 issue, with intense keywords, such as "china", "viral" and "pneumonia" in addition to the keyword "coronavirus". The third group has quite a lot to do with the first two groups in the context of the issues used, so it concluded that the study of COVID-19 received enough attention in communication studies.

In the research articles on Garuda and Google Scholar databases, the three main issues that develop consist of group 1 ("government policy", "economy", "health protocol", "human rights", "Islam", "fatwa", "tourism" etc.), group 2 ("education”, "effectiveness", "blended learning”, "e-learning”, "distance learning" etc.), group 3 ("anxiety", "Attitude”, "behavior", "literacy", "social media", etc.). It was in line with the issues contained in Scopus indexed publications, where researchers in the social and humanities field focus their studies on government policies related to COVID-19.

The differences are second and third, where the Scopus database focuses on social issues, psychology is related to changing attitudes and behavior in a new society. Meanwhile, social science studies place the issue of education in the pandemic era as the second issue. 
The focus on education issues in social journal articles in Indonesian next cluster group, from group 4 ("children," "home", "learning", "communication"), group 5 ("china", "corona", " economic crisis "), group 6 (" computer science "," social science "," humanities ", etc.) and group 7 (" education, Islam, online learning ", global pandemic "and” government policy "). Briefly, education is the dominant issue discussed in articles related to COVID-19, but scattered into several small clusters.

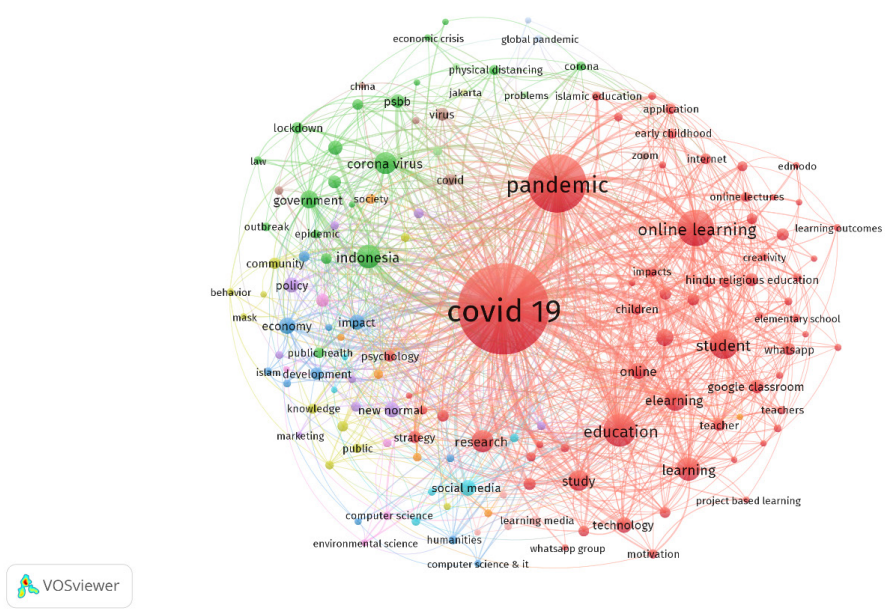

Figure 5 Social Humanities Research in Garuda and Google Scholar Database

It is quite interesting from the Garuda and Google Scholar databases, that many articles link the COVID-19 issue with the keyword "islam". Several journals that intensively publish journal articles come from journals from Islamic universities. Such as the journal "Adalah, Buletin Hukum \& Keadilan (eISSN: 26549050) and Salam: Jurnal Sosial Budaya Syar-i(ISSN 2654905), both of which are affiliated with the Syarif Hidayatullah State Islamic University Jakarta.

The same explanation is also related to the keyword "hindu". This term is also found because the journal Ganaya from Jayapangus Press (e-ISSN: 2615 0913) is a journal of Social Humanities from Bali which adequately studies the impact of COVID-19 in the world of education and tourism. Although their affiliation is not visible on the website page, the editors mostly come from the Hindu Dharma Institute, Denpasar, Bali. Jayapangus Press also published the journal Cetta: Jurnal Ilmu Pendidikan (eISSN: 26150891), which has the 
second-highest number of articles related to COVID-19.

Furthermore, we look at articles in communication journals. We have selected journals based on the article theme and journal identity (name, scope, purpose, and affiliated journals) from the Garuda and Google Scholar databases. Next, we lowered the threshold for occurrence keywords and chose fraction normalization to visualize research article data because of insufficient data.

Figure 6 shown that communication and COVID-19 keyword are culstered into several groups, group 1 ("community", "education", "media", "pandemic" etc.), group 2 ("coronavirus", "epidemic", " government "," government policy "," PSBB "," lockdown "), group 3 (" attitude "," customer "," "social media" and "technology”), group 4 (“application”, "distance learning “," Education "” e-learning "), group 5 (" public education "," social distancing "," physical distancing "), group 6 (" learning media "," literacy ") and group 7 (" marketing “, "MSME” / Micro, Small Medium Enterprise / UMKM).

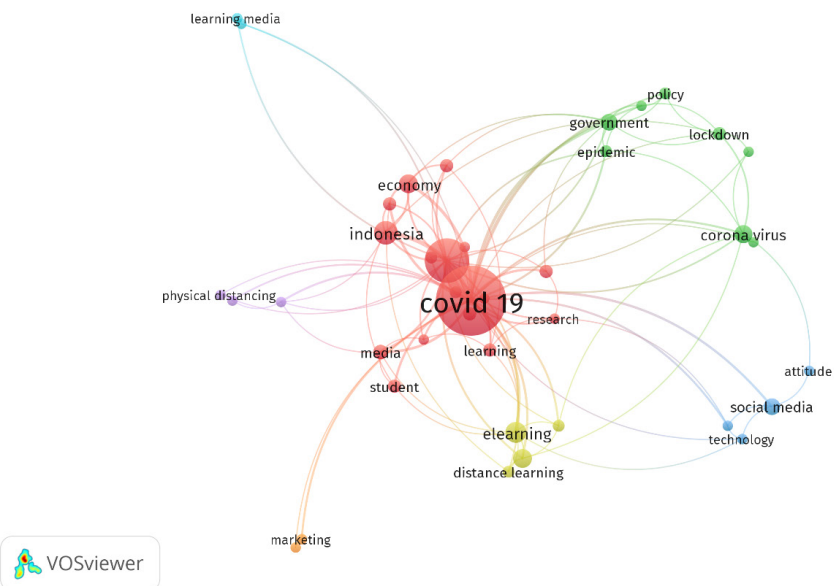

Figure 6 Communication Research in the Garuda Database and Google Scholar

This overview generally guides the issue of COVID-19 in Indonesia communication science studies in Indonesia on several themes, namely a) health communication in government policies regarding PSBB/Lockdown, social distancing and physical distancing, b) social media and behavior change, c) media technology in distance learning and e) economy impact in media. 
Meanwhile, COVID-19 related to media issues and disinformation, family communication, and political communication/media framing, and cultural studies and social identity does not appear yet in keywords during the span of this research.

\section{Discussion}

The results have shown that COVID-19 in social studies, humanities, and communication influenced at least; first, the interdisciplinary vision and scope of the journal; second, editorial policy covering special editions related to the COVID-19 theme; third, format, and edition of journal publications.

First, the vision and scope of a journal determine the number of articles covering the COVID-19 issue. For multidisciplinary social science journals, published journal articles come from a variety of perspectives and approaches. Meanwhile, in monodisciplinary journals, including several well-known and highly ranked communication science journals, the COVID-19 issue appears along with other unrelated communication issues.

Second, editorial policy determines the issues to be covered. Although it is not reflected directly in the number of articles published, it is encouraged to increase articles related to COVID-19. This policy also leads forms a linear knowledge space with the objectives and scope of the journal itself.

Third, the type and format of the journal. Journals in the Open Access model with short periodicals time has more COVID-19 articles compared to conventional journals that have longer periodicals time. Furthermore, This research data has illustrated that journal affiliations in Indonesia determine the keywords that appear and use in published articles related to COVID-19.

We found a similar pattern from Scopus, Garuda, and Google Scholar, that the research themes for social sciences are government policies, changes in attitudes and behavior, and education. Meanwhile, on the communication science side, studies that have emerged have linked COVID-19 to health communication, crisis communication, and the role of information technology in education. Media studies in the credibility of information, disinformation, fake news, and social media, while the perspective of normative studies of media is not very visible yet.

In research articles from Indonesian journals, there are common topics in social sciences and humanities with articles' topics from international research, although there are more studies on education. Meanwhile, in communication 
journals, the research problem has not been fully explored. It leads to the question of the relevance of normative media effects theory; a) whether information technology has change mass media roles, b) how the media are causing profound changes in self-identity and social-interaction. In other fields, behaviorism researchers gain momentum to study changes in attitudes and behavior at the individual, organizational and social levels.

This research has limitations, especially in terms of exploring the contents of the article in detail. This research only looks at the big picture of the COVID-19 studies in Social Humanities and Communication Science, but it cannot describe discourse in detail. For this reason, we need a systematic literature review to obtain a deeper picture of the contents of the article, starting from the research problems, theory, methods, and conclusions remarks.

\section{Conclusion}

COVID-19 is a very "trend-prone" issue in contemporary studies, where each researcher is competing to publish his research work quickly. It implies that many novice researchers - in the sense of being professional researchers or in the context of senior researchers researching a new issue, in the case of COVID-19) are trying to study COVID-19 from a social, humanities, and communication perspective as quickly as well.

Communication scholars can start with ontological questions about various communication theories that have been researched and contextualized in the study of COVID-19, not only explaining the COVID-19 in perspectives of communication science studies but placing it in a continuum of rediscovery to communication scholarship(Kling \& McKim, 1999). 
The impact of editorial policies and journal models ...(Mahfud Anshori,Henricus Hans Setyawan Prabowo)

\section{References}

Achwan, R., Ganie-Rochman, M., Alamsyah, A. R., \& Triana, L. (2020). University reform and the development of social sciences in Indonesia. International Journal of Educational Development, 78(December 2019), 102269. https://doi.org/10.1016/j.ijedudev.2020.102269

Dey, E. L., \& Milem, J. F. (2016). Changing patterns of publication productivity: Accumulative advantage or institutional isomorphism? Author (s): Eric L. Dey , Jeffrey F. Milem and Joseph B. Berger Published by: American Sociological Association Stable URL: http://www.jstor.org/s. 70(4), 308-323.

Goodrum, A. A., McCain, K. W., Lawrence, S., \& Lee Giles, C. (2001). Scholarly publishing in the Internet age: A citation analysis of computer science literature. Information Processing and Management, 37(5), 661-675. https://doi.org/10.1016/S0306-4573(00)00047-9

Harnad, S. (1990). Scholarly Skywriting and the Prepublication Continuum of Scientific Inquiry. 1(6), 342-344.

Johns Hopkins University. (2021). COVID-19 Dashboard by the Center for Systems Science and Engineering (CSSE) at Johns Hopkins University (JHU). $\quad$ https://www.arcgis.com/apps/opsdashboard/index.html\#/ bda7594740fd40299423467b48e9ecf6

Kling, R., \& McKim, G. (1999). Scholarly communication and the continuum of electronic publishing. Journal of the American Society for Information Science, 50(10), 890-906. https://doi.org/https://doi.org/10.1002/ (SICI) 1097-4571(1999)50:10<890::AID-ASI6>3.0.CO;2-8

Kronick, D. A. (1990). Peer review in 18th-century scientific journalism. JAMA: The Journal of the American Medical Association, 263(10), 1321-1322. https://doi.org/10.1001/jama.263.10.1321

Kuney, J. H. (1970). New Developments in Primary Journal Publication. Journal of Chemical Documentation, 10(1), 42-46. https://doi.org/10.1021/ c160036a015

Liu, Z. (2003). Trends in transforming scholarly communication and their implications. Information Processing and Management, 39(6), 889-898. https://doi.org/10.1016/S0306-4573(02)00057-2

Mansourzadeh, M. J., \& Shamsi, A. (2020). Concerns About Research Ethics in COVID-19 Publications. Asia-Pacific Journal of Public Health, 32(8), 
503-504. https://doi.org/10.1177/1010539520956439

Martin, B. R. (2011). What can bibliometrics tell us about changes in the mode of knowledge production? Prometheus (United Kingdom), 29(4), 455-479. https://doi.org/10.1080/08109028.2011.643540

Metz, P., \& Gherman, P. M. (1991). Serials pricing and the role of the electronic journal. College and Research Libraries, 52(4), 315-327. https://doi. org/10.5860/crl_52_04_315

Moradi, S., \& Abdi, S. (2020). Pandemic publication: correction and erratum in COVID-19 publications. Scientometrics, 126(2), 1849-1857. https:// doi.org/10.1007/s11192-020-03787-w

Odlyzko, A. M. (1995). Tragis loss or good riddance? The impending demise of traditional scholarly journals. International Journal Human Computer Studies, 42, 71-122.

Perrucci, R., Perrucci, C., \& Subramaniam, M. (2019). Publications in Four Sociology Journals, 1960-2010: The Role of Discipline Demographics and Journal Mission. Sociological Focus, 52(3), 171-185. https://doi.org/ 10.1080/00380237.2019.1624232

Sobal, Jefferey, Ferentz, K. S. (1990). Abstract Creep and Author Inflation. The New England Journal of Medicine, 323(16), 1120-1123.

Søgaard, A., Vulin, I., Ruder, S., \& Faruqui, M. (2019). Cross-Lingual Word Embeddings. In Synthesis Lectures on Human Language Technologies (Vol. 12, Issue 2, pp. 1-132). https://doi.org/10.2200/ S00920ED2V01Y201904HLT042

Soltani, P., \& Patini, R. (2020). Retracted COVID-19 articles: a side-effect of the hot race to publication. Scientometrics, 125(1), 819-822. https://doi. org/10.1007/s11192-020-03661-9

Watson, J. D. (1958). The Publishing Game: Getting More for Less Meet the Least Publishable Unit, How does the editor of the New England Sociologists say paper inflation is growing to the point that it is possible. 1137-1139. 